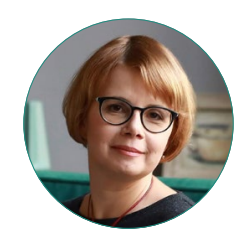

М. А. Карцева

\title{
ЗАНЯТОСТЬ И ЗДОРОВЬЕ “СЭНДВИЧ-ПОКОЛЕНИЯ" В РОССИИ: ЭМПИРИЧЕСКИЙ АНАЛИЗ
}

\section{Правильная ссылка на статью:}

Карцева М. А. Занятость и здоровье “сэндвич-поколения" в России: эмпирический анализ // Мониторинг общественного мнения: экономические и социальные перемены. 2021. № 5. C. 324-344. https://doi.org/10.14515/monitoring.2021.5.1844.

\section{For citation:}

Kartseva M. A. (2021) Employment and Health of the Sandwich Generation in Russia: Empirical Analysis. Monitoring of Public Opinion: Economic and Social Changes. No. 5. P. 324-344. https://doi.org/10.14515/monitoring.2021.5.1844. (In Russ.) 
ЗАНЯТОСТЬ И ЗДОРОВЬЕ «СЭНДВИЧПОКОЛЕНИЯ" В РОССИИ: ЭМПИРИЧЕСКИЙ АНАЛИЗ

КАРЦЕВА Марина Анатольевна - кандидат экономических наук, старший научный сотрудник Института социального анализа и прогнозирования, Российская академия народного хозяйства и государственной службы при Президенте РФ, Москва, Россия

E-MAIL: mkartseva@mail.ru https://orcid.org/0000-0002-4292-3597

Аннотация. В работе изучается влияние "сэндвич-синдрома" на занятость и здоровье индивидов в России. Мы полагаем, что человек испытывает "Сэндвич-синдром", если предоставляет услуги неформального ухода двум поколениям. Оценивание эффекта “сэндвич-синдрома" проводится методом мэтчинга. Эмпирической базой исследования являются микроданные Выборочного наблюдения использования суточного фонда времени населением, проведенного Росстатом в 2019 году. Выявлено, что в целом “сэндвич-синдром" оказывает негативное влияние на вероятность занятости индивидов, увеличивает вероятность дистанционной занятости, но не влияет на заработную плату. Наличие "сэндвичсиндрома" не влияет на самооценку здоровья индивидов, но увеличивает вероятность наличия хронических заболеваний. Люди, ухаживающие за двумя поколениями, чаще испытывают чувство нехватки времени и имеют меньше свободного времени. Величина и значимость эффекта "сэндвичсиндрома" варьируется в зависимости от типа контрольной группы (не испытывающие "сэндвич-синдром"; ни за кем не ухаживающие; ухаживающие толь-
EMPLOYMENT AND HEALTH OF THE SANDWICH GENERATION IN RUSSIA: EMPIRICAL ANALYSIS

Marina A. KARTSEVA ${ }^{1}$ - Cand. Sci. (Econ.), Senior Research Fellow, Institute of Social analysis and Forecasting

E-MAIL: mkartseva@mail.ru https://orcid.org/0000-0002-4292-3597

\footnotetext{
1 The Russian Presidential Academy of National Economy and Public Administration (RANEPA), Moscow, Russia
}

Abstract. The work examines the influence of the sandwich syndrome on the employment and health of individuals in Russia. We consider a person to experience sandwich syndrome if they provide informal care for two generations. To evaluate this effect, we utilized the matching procedure. The empirical basis of the study is the microdata of nationally representative time-budget survey, conducted by Rosstat in 2019. Our study reveals that in general the sandwich syndrome negatively affects the probability of the individual's employment, increases the likelihood of their distance job but does not affect their wages. sandwich syndrome does not impact on the individual self-assessment of health but increases the likelihood of chronic diseases. People with sandwich syndrome are more likely to feel time pressure and have less free time. The magnitude and significance of the sandwich syndrome effect varies depending on the type of control group (not experiencing sandwich syndrome; not caring for anyone; caring only for children; caring for adults only). 
ко за детьми; ухаживающие только за взрослыми).

Ключевые слова: сэндвич-поколение, сэндвич-синдром, неформальный уход, занятость, здоровье, мэтчинг, Россия

Благодарность. Статья подготовлена в рамках выполнения научно-исследовательской работы государственного задания РАНХиГС.

Автор выражает свою искреннюю признательность И. А. Денисовой, М.Г. Колосницыной и анонимному рецензенту за чрезвычайно полезные замечания и комментарии.
Keywords: sandwich generation, sandwich syndrome, informal care, employment, health, Russia, matching

Acknowledgments. The article was prepared as part of research on the state assignment of the RANEPA.

The author expresses her appreciation to I. A. Denisova, M. G. Kolosnitsyna as well as to anonymous referees for extremely valuable remarks and comments.

\section{Введение}

В современном постиндустриальном обществе межпоколенные связи остаются важнейшим источником помощи и поддержки в сложных ситуациях [Bengtson, Roberts, 1991; Brandt, Haberkern, Szydlik, 2009; Fokkema, Bekke ter, Dykstra, 2008; Silverstein, Gans, Yang, 2006; Silverstein, Bengtson, 1997]. Межпоколенная солидарность позволяет компенсировать несовершенство существующих социальных институтов, особенно в части ухода за детьми и пожилыми людьми. Одна из важнейших форм проявления межпоколенной солидарности - временные трансферты от одного поколения к другому.

Объемы временных трансфертов неравномерно распределены между поколениями. Сложившаяся демографическая структура и социально-экономическая ситуация приводят к тому, что среднее поколение испытывает наибольшую нагрузку. Увеличение продолжительности жизни привело к росту спроса на услуги ухода со стороны родительского поколения. В условиях несовершенства систем долговременного ухода существенная часть работы и затрат по уходу за старшим поколением ложится на их взрослых детей. Ситуация усугубляется низким уровнем рождаемости в родительском поколении - если раньше многочисленные братья и сестры могли разделить между собой заботы по уходу за пожилыми родителями, то сейчас вся нагрузка часто ложится на единственного ребенка, представителя среднего поколения. Другая демографическая тенденция, связанная с откладыванием вступления в брак и увеличением возраста рождения детей среди представителей среднего поколения, также повышает социальную нагрузку - у представителей среднего поколения могут быть несовершеннолетние дети, нуждающиеся в заботе. Таким образом, люди среднего возраста часто испытывают двойную нагрузку, одновременно заботясь о своих детях и о своих родителях. Не случайно в социологической литературе среднее поколение полу- 
чило название "сэндвич-поколение" (sandwich generation), эти люди как будто с двух сторон зажаты обязанностями [Miller, 1981]. В настоящее время в литературе также часто используется понятие "сэндвич-синдром". Оно основывается не на демографических характеристиках индивида, а на его фактической вовлеченности в уход. Считается, что человек испытывает "сэндвич-синдром", если он одновременно ухаживает за представителями младшего и старшего поколения ${ }^{1}$.

Особенности социально-экономического положения, физического и психического здоровья "сэндвич-поколения" широко обсуждаются в зарубежной экономической, социологической и медицинской литературе. В частности, на основе национально репрезентативных данных показано, что "сэндвич-синдром" негативно отражается на различных характеристиках занятости жителей развитых стран. Ухаживающие за двумя поколениями сокращают предложение труда - у них ниже вероятность занятости и выше вероятность неполной занятости [Pagani, Marenzi, 2008; Bardoel, Drago, 2016; Daatland, Veenstra, Lima, 2010]. Люди, испытывающие "сэндвич-синдром", в меньшей степени удовлетворены количеством часов работы на рынке труда - они предпочли бы посвящать работе больше времени [Rubin, White-Means, 2009].

"Сэндвич-синдром" также оказывает влияние на состояние здоровья ухаживающих. Вовлеченность в уход за двумя поколениями снижает самооценку здоровья [Do, Cohen, Brown, 2014; Daatland, Veenstra, Lima, 2010; Häusler, Hämmig, Bopp, 2018]. Совмещение родительских обязанностей и неформального ухода за родителями, значимо увеличивает уровень стресса индивидов и снижает количество свободного времени [Rubin, White-Means, 2009], повышает вероятность дистресса [Voydanoff, Donnelly, 1999], провоцирует депрессивные состояния [Brenna, 2020] и оказывает негативное влияние на вероятность использования различных самосохранительных практик [Chassin et al., 2010].

В России проблема “сэндвич-поколения" особенно актуальна. Увеличение нагрузки на среднее поколение, вызванное демографическими процессами, в России происходит на фоне низкого уровня развития социальных услуг и в особенности системы долговременного ухода. Если в уходе за детьми родители могут рассчитывать поддержку со стороны государства (хотя объем и разнообразие форм такой поддержки часто подвергаются критике [Овчарова, 2008; Волкова, Кудаева, 2019]), то уход за пожилыми родственниками в России в основном ложится на членов семьи [Корчагина, Прокофьева, 2012; Краснова, 2001]. Обращение к услугам формального ухода является, как правило, вариантом "последнего выбора" [Смирнова, Смирнов, 2020]. Таким образом, можно предположить, что "сэндвич-синдром" является достаточно распространенным явлением в России.

В российской научной литературе показано, что уход за детьми негативно влияет на различные аспекты занятости родителей, особенно матерей. Для женщин наличие детей снижает вероятность занятости, увеличивает вероятность неполной занятости, оказывает негативное влияние на величину заработной платы (например, [Пайе, Синявская, 2010; Карабчук, Нагерняк, 2013; Казакова, 2012; Арженовский, Артамонова, 2007; Бирюкова, Макаренцева, 2017]). Отдельные

\footnotetext{
1 Здравомыслова Е. О “сэндвич-синдроме»//Демоскоп Weekly. 2016. № 677-678. http://www.demoscope.ru/ weekly/2016/0677/gazeta031.php (дата обращения: 01.11.2021).
} 
работы показывают, что уход за детьми в ряде случаев приводит к высокому уровню родительского стресса, который может негативно влиять на психическое и физическое здоровье [Аникина, Пшонова, 2019; Савенышева, Заплетина, 2019]. Неформальный уход за пожилыми родственниками значительно ухудшает эмоциональное и психологическое состояние ухаживающих, увеличивает вероятность возникновения стресса и депрессии, хронических заболеваний, снижает самоооценку здоровья. Также уход за пожилыми часто связан с отказом от работы на рынке труда или с существенным сокращении занятости [Гришина, Цацура, 2020; Ткач, 2015; Здравомыслова, Савченко, 2020; Мальцева и др., 2016; Зимнякова и др., 2012]. Результаты исследований позволяют сформулировать гипотезу о том, что в России люди, испытывающие "сэндвич-синдром", представляют собой особенно уязвимую группу. Уход за двумя поколениями может увеличивать вероятность наличия проблем со здоровьем и занятостью как по сравнению с теми, кто ни за кем не ухаживает, так и по сравнению с теми, кто ухаживает только за одним поколением.

В российской научной литературе объем исследований, посвященных проблемам “сэндвич-поколения" очень ограничен. Большой вклад в привлечение внимания к проблемам сэндвич-поколения в России внесла социолог, профессор факультета социологии и философии Европейского университета в Санкт-Петербурге Елена Здравомыслова ${ }^{2}$. Такие негативные последствия "сэндвич-синдрома", как ухудшение характеристик занятости и эмоциональное выгорание, отмечаются в работе [Ткач, 2015]. Сокращение занятости, нарастание психологических трудностей, сокращение свободного времени отмечаются в работе [Шерешева и др., 2015]. Все эти работы выполнены на основе качественных социологических исследований. Насколько нам известно, до настоящего времени в РФ не проводился количественный анализ влияния "сэндвич-синдрома" на социальноэкономическое положение и здоровье индивидов.

Основной целью данной работы является получение количественных оценок влияния ухода за двумя поколениям на показатели занятости и здоровья населения с использованием национально репрезентативных данных.

\section{Эмпирическая база. Построение переменных}

\section{1. Эмпирическая база}

Эмпирическая основа исследования - микроданные Выборочного наблюдения использования суточного фонда времени населением, проведенного Росстатом в 2019 г. (ВНИСФВ-2019) ${ }^{3}$. Основная задача обследования - получение достоверной статистической информации о затратах времени на оплачиваемый труд, на обучение, на труд, осуществляемый в личном подсобном хозяйстве, на ведение домашнего хозяйства, на уход за детьми, а также на досуг и отдых.

Единицей отбора в рамках Выборочного наблюдения использования суточного фонда времени населением является домохозяйство. Выборочная совокупность

\footnotetext{
2 См., например, Здравомыслова Е. О “сэндвич-синдроме»//Демоскоп Weekly. 2016. № 677-678. http://www. demoscope.ru/weekly/2016/0677/gazeta031.php (дата обращения: 01.11.2021).

3 Микроданные ВНИСФВ-2019 находятся в открытом доступе на сайте Росстата. URL: https://rosstat.gov.ru/free_doc/ new_site/population/urov/sut_fond19/index.html (дата обращения: 28.10.2021).
} 
формируется на базе данных Всероссийской переписи населения 2010 г. с помощью случайного двухступенчатого отбора. Опрос проводится во всех субъектах РФ. Охват обследования - 45 тысяч домохозяйств.

Инструментарий обследования включает в себя специализированную форму наблюдения - дневник использования времени, который заполняется респондентом самостоятельно и содержит информацию о видах деятельности и времени их осуществления в течение 24 часов. Дневник позволяет получить информацию о деятельности индивида по десятиминутным интервалам. Каждый респондент заполняет два дневника: один в будний день и один в выходной день. Дополнительно инструментарий обследования содержит вопросник для лиц старше 15 лет, включающий в себя вопросы о занятости индивида, его образовании и здоровье.

Таким образом, в результате обследования формируется уникальный массив данных, интегрирующий в себе информацию о том, как индивиды используют время, а также данные о социально-демографическом и экономическом положении индивидов и их домохозяйств.

\section{2. Определение "сэндвич-синдрома". Описательные статистики}

В фокусе нашей работы - люди в возрасте от 30 до 60 лет, испытывающие "сэндвич-синдром", то есть осуществляющие одновременно уход за двумя поколениями. Микроданные дневников ВНИСФВ-2019 позволяют определить, занимался ли индивид уходом за детьми и/или взрослыми на безвозмездной основе в день заполнения дневника. Под уходом за детьми понимаются такие виды деятельности как обеспечение питания, физический уход, мытье, медицинский уход, воспитание, обучение, подготовка и помощь, разговоры с детьми, игры и занятия спортом с ними, присмотр, сопровождение и пр. Уход за взрослыми включает в себя обеспечение питания, физический уход, медицинский уход, содействие в заполнении форм, управлении делами, присмотр, эмоциональную поддержку, сопровождение и пр. Мы считаем, что человек испытывает "сэндвич-синдром", если в течение двух дней, в которые происходило заполнение дневников, он хотя бы один раз оказывал услуги неформального ухода детям и хотя бы один раз оказывал услуги неформального ухода взрослым. При этом не имеет значения, оказывал ли индивид услуги неформального ухода лицам, проживающим в его домохозяйстве или в другом домохозяйстве.

Расчеты показали, что “сэндвич-синдром" испытывают 7,9\% населения России. В таблице 1 представлены основные социально-демографические характеристики населения, испытывающего и не испытывающего "сэндвич-синдром" 4 . Практически три четверти (72\%) людей, испытывающих "сэндвич-синдром" - женщины. По сравнению с мужчинами они гораздо чаще оказываются "Внутри сэндвича". В этом смысле Россия не исключение - женщины чаще ухаживает одновременно за двумя поколениями как в развитых, так и в развивающихся странах (например, [Pierret, 2006]). Люди, испытывающие "сэндвич-синдром", в среднем моложе тех, кто его не испытывает (40 лет против 46 лет). Около двух третей испытывающих “сэндвич-синдром" относятся к возрастной группе 30-39 лет. С воз-

\footnotetext{
4 Здесь и далее люди, не испытывающие "сэндвич-синдром", определяются как люди, не вовлеченные одновременно в уход за двумя поколениями
} 
растом вовлеченность в уход за двумя поколениями снижается. Наблюдаются некоторые различия в образовательной структуре лиц, испытывающих “сэндвичсиндром" и лиц, не испытывающих "сэндвич-синдром". Например, среди тех, кто испытывает "сэндвич-синдром" доля лиц с высшим образованием существенно превышает аналогичный показатель для тех, кто не испытывает синдром (50\% против 38\%). Частично различия образовательной структуры могут быть объяснены различиями возрастной структуры: в России в более молодых когортах отмечается более высокая распространенность высшего образования. Три четверти (73\%) людей, испытывающих "сэндвич-синдром", проживают в городах. Среди не испытывающих "сэндвич-синдром" доля сельских жителей несколько ниже - $68 \%$. Таким образом, рассматриваемые группы населения значительно различаются по своим социально-демографическим характеристикам ${ }^{5}$. При этом наблюдаемая структура различий сохраняется при сопоставлении испытывающих "сэндвич-синдром", и различных подгрупп лиц, не испытывающих "сэндвич-синдром" (не ухаживают ни за кем, ухаживающие только за детьми и ухаживающие только за взрослыми). При этом наиболее близкой по своей социально-демографической структуре к ухаживающим за двумя поколениями подгруппой людей, не испытывающих “сэндвич-синдром», являются люди, ухаживающие только за детьми.

Таблица 1. Основные социально-демографические характеристики населения, испытывающего и не испытывающего “сэндвич-синдром"

\begin{tabular}{|c|c|c|c|c|c|}
\hline & \multirow[b]{2}{*}{$\begin{array}{c}\text { Население, } \\
\text { испытывающее } \\
\text { "сэндвич- } \\
\text { синдром" }\end{array}$} & \multirow[b]{2}{*}{$\begin{array}{c}\text { Население, } \\
\text { не испытываю- } \\
\text { щее "сэндвич- } \\
\text { синдром" }\end{array}$} & \multicolumn{3}{|c|}{ Среди них: } \\
\hline & & & $\begin{array}{c}\text { Не уха- } \\
\text { живают } \\
\text { ни за кем }\end{array}$ & $\begin{array}{c}\text { Ухаживают } \\
\text { только } \\
\text { за детьми }\end{array}$ & \begin{tabular}{|l} 
Ухаживают \\
только \\
за взрос- \\
лыми
\end{tabular} \\
\hline \multicolumn{6}{|l|}{ Пол } \\
\hline Женщины, \% & 72 & 58 & 54 & 66 & 52 \\
\hline Мужчины, \% & 28 & 42 & 46 & 34 & 48 \\
\hline \multicolumn{6}{|l|}{ Возраст } \\
\hline $\begin{array}{l}\text { Средний возраст, } \\
\text { лет }\end{array}$ & 40 & 46 & 48 & 40 & 49 \\
\hline 30-39 лет, \% & 62 & 32 & 19 & 57 & 16 \\
\hline 40-49 лет, \% & 24 & 30 & 31 & 28 & 31 \\
\hline 50-60 лет, \% & 14 & 38 & 50 & $15^{\circ}$ & 53 \\
\hline \multicolumn{6}{|c|}{ Образование (наивысший достигнутый уровень) } \\
\hline $\begin{array}{l}\text { Среднее общее } \\
\text { и ниже, \% }\end{array}$ & 12 & 15 & 16 & $13^{0}$ & 15 \\
\hline $\begin{array}{l}\text { Начальное профес- } \\
\text { сиональное, \% }\end{array}$ & 7 & 10 & 11 & 8 & 11 \\
\hline $\begin{array}{l}\text { Среднее профессио- } \\
\text { нальное, \% }\end{array}$ & 32 & 37 & 39 & 34 & 42 \\
\hline
\end{tabular}

5 Проверка значимости различий социально-демографических характеристик между группами людей, не испытывающих "сэндвич-синдром", и людьми, испытывающими "сэндвич-синдром", проводилась с помощью теста Стьюдента на равенство средних. Средние значения большинства рассматриваемых показателей для не испытывающих “сэндвич-синдром" значимо отличаются от аналогичных показателей для испытывающих "сэндвич-синдром" (не менее чем на 5 \% уровне значимости). Детальные результаты статистического анализа могут быть высланы по запросу. 


\begin{tabular}{|c|c|c|c|c|c|}
\hline & \multirow[b]{2}{*}{$\begin{array}{c}\text { Население, } \\
\text { испытывающее } \\
\text { "сэндвич- } \\
\text { синдром" }\end{array}$} & \multirow[b]{2}{*}{$\begin{array}{c}\text { Население, } \\
\text { не испытываю- } \\
\text { щее "сэндвич- } \\
\text { синдром" }\end{array}$} & \multicolumn{3}{|c|}{ Среди них: } \\
\hline & & & $\begin{array}{c}\text { Не уха- } \\
\text { живают } \\
\text { ни за кем }\end{array}$ & $\begin{array}{c}\text { Ухаживают } \\
\text { только } \\
\text { за детьми }\end{array}$ & \begin{tabular}{|c|} 
Ухаживают \\
только \\
за взрос- \\
лыми
\end{tabular} \\
\hline $\begin{array}{l}\text { Высшее профессио- } \\
\text { нальное, \% }\end{array}$ & 50 & 38 & 35 & 45 & 32 \\
\hline \multicolumn{6}{|l|}{ Место проживания } \\
\hline Город, \% & 73 & 68 & 66 & 71 & 68 \\
\hline Село, \% & 27 & 32 & 34 & 29 & 32 \\
\hline $\begin{array}{l}\text { Количество } \\
\text { наблюдений }\end{array}$ & 3148 & 36630 & 22380 & 12410 & 1840 \\
\hline
\end{tabular}

Примечание. 0-статистически значимо не отличается от аналогичного показателя для людей, испытывающих "Сэндвич-синдром".

Источник: расчеты автора на данных ВНИСФВ-2019.

\section{3. Показатели занятости и здоровья. Описательные статистики}

Отбор показателей занятости и здоровья индивидов в работе осуществлялся исходя из поставленной задачи, с учетом опыта исследований по данной тематике и наличия данных в массиве ВНИСФВ-2019.

В качестве показателей, характеризующих занятость индивидов, в работе используются:

- Наличие у респондента оплачиваемой занятости. Индивид считался занятым, если на неделе, предшествующей опросу, он выполнял какую-либо оплачиваемую работу или находился в отпуске/на больничном. Занятыми также считались люди, которые не работали в указанную неделю, в силу специфики режима работы.

- Дистанционная занятость. Мы полагали, что занятость индивида является дистанционной, если большую часть рабочего времени он работает дистанционно (с использованием сети Интернет) или работает дома (надомная работа).

- Гибкая занятость. При определении гибкой занятости мы использовали информацию о рабочем графике индивида. Занятость считалась гибкой, если человек работает в режиме гибкого рабочего времени.

- Заработная плата. В качестве заработной платы в работе использовалось значение чистого дохода индивида от трудовой деятельности в среднем за месяц с начала года. Для обеспечения региональной сопоставимости в работе зарплата измеряется как отношение номинальной заработной платы и величины регионального прожиточного минимума за 2019 г.

Для анализа эффекта "сэндвич-синдрома" на здоровье индивидов в работе используются:

- Самооценка здоровья (хорошее и очень хорошее). Данная переменная сконструирована на основе оценки индивидами собственного здоровья. Переменная принимает значений 1, если человек оценивает свое здоровье как хорошее или очень хорошее, и 0, если человек оценивает свое здоровье как удовлетворительное, плохое или очень плохое. Хотя самооценка не является объективной с медицинской точки зрения оценкой здоровья индивида, она остается важным 
предиктором заболеваемости и смертности (например, [ldler, Benyamini, 1997; Wu et al., 2013], особенно для людей среднего возраста [Miilunpalo et al., 1997]).

- Наличие хронических заболеваний. В работе предполагалось, что у индивида есть хроническое заболевание, если в ходе опроса он отметил, что у него есть какой-либо, установленный врачом диагноз, включая перенесенные инфаркт и инсульт.

- Чувство постоянной нехватки времени. Данный показатель был построен на основе ответов респондентов ВНИСФВ-2019 о том, как часто им не хватает времени. Показатель принимает значение 1, если человек всегда чувствует нехватку времени, спешку, и О в противном случае.

- Свободное время. Количество свободного времени в день было рассчитано на основе данных дневников использования времени и определялось как среднее количество свободного времени в день за те два дня, в которые велось заполнения дневника.

Как и самооценка здоровья, чувство постоянной нехватки времени и количество свободного времени не являются непосредственными индикаторами здоровья. Однако они также являются важными детерминантами состояния здоровья. Постоянное чувство спешки и недостаток отдыха, увеличивают вероятность депрессии и стресса и могут представлять существенную угрозу физическому и психическому здоровью человека [Gomez-Bernal et. al, 2019].

Средние значения используемых показателей занятости и здоровья испытывающих "сэндвич-синдром", а также различных групп лиц, не испытывающих "сэндвич-синдром" приведены в таблице 2. Результаты статистического анализа ${ }^{6}$ показывают, что по сравнению с теми, кто не испытывает сэндвич-синдром, люди, вовлеченные в уход за двумя поколениями, реже имеют оплачиваемую занятость и чаще работают дистанционно. Показатели распространенности гибкой занятости среди рассматриваемых двух групп населения статистически не отличаются. Средняя зарплата в группе занятых, испытывающих "сэндвич-синдром", несколько выше, чем среди занятых, не испытывающих "сэндвич-синдром", однако величина различий не значительна. В среднем, люди, испытывающие, "сэндвич-синдром" чаще оценивают свое здоровье как хорошее или очень хорошее, реже имеют хронические заболевания. Они имеют меньше свободного времени и чаще испытывают постоянное чувство нехватки времени.

Однако наблюдаемые различия характеристик здоровья и занятости не могут быть истолкованы как эффект "сэндвич-синдрома", при определении которого необходимо учитывать различия социально-демографической структуры людей, испытывающих "сэндвич-синдром", и тех, кто его не испытывает. Эти различия во многом могут определять вариацию показателей занятости и здоровья между группами. Для этого необходимо применение специализированных эконометрических методик (см. раздел 3).

\footnotetext{
6 Проверка значимости различий характеристик здоровья и занятости между группами людей, не испытывающих "сэндвич-синдром", и людьми, испытывающими "сэндвич-синдром", проводилась с помощью теста Стьюдента на равенство средних. Средние значения большинства рассматриваемых показателей для не испытывающих "сэндвич-синдром" значимо отличаются от аналогичных показателей для испытывающих "сэндвич-синдром" (не менее чем на $5 \%$ уровне значимости). Детальные результаты статистического анализа могут быть высланы по запросу.
} 
Таблица 2. Показатели занятости и здоровья населения, испытывающего и не испытывающего "сэндвич-синдром"

\begin{tabular}{|c|c|c|c|c|c|}
\hline \multirow[b]{2}{*}{ Показатель } & \multirow[b]{2}{*}{$\begin{array}{l}\text { Испытывают } \\
\text { "сэндвич- } \\
\text { синдром" }\end{array}$} & \multirow[b]{2}{*}{$\begin{array}{c}\text { Не } \\
\text { испытывают } \\
\text { "сэндвич- } \\
\text { синдром" }\end{array}$} & \multicolumn{3}{|c|}{ Среди них: } \\
\hline & & & $\begin{array}{c}\text { Не уха- } \\
\text { живают } \\
\text { ни за кем }\end{array}$ & $\begin{array}{c}\text { Ухаживают } \\
\text { только } \\
\text { за детьми }\end{array}$ & $\begin{array}{l}\text { Ухаживают } \\
\text { только } \\
\text { за взрос- } \\
\text { лыми } \\
\end{array}$ \\
\hline \multicolumn{6}{|l|}{ Занятость } \\
\hline Занятость, \% & 73 & 80 & 80 & 81 & $72^{\circ}$ \\
\hline $\begin{array}{l}\text { Дистанционная } \\
\text { занятость, \% } \\
\text { (от занятых) }\end{array}$ & 2,8 & 1,5 & 1,4 & 1,8 & 1,4 \\
\hline $\begin{array}{l}\text { Гибкая занятость, \% } \\
\text { (от занятых) }\end{array}$ & 12 & $13^{0}$ & 13 & $12^{0}$ & 16 \\
\hline $\begin{array}{l}\text { Средняя заработная } \\
\text { плата, пМ в месяц }\end{array}$ & 2,4 & 2,3 & 2,3 & $2,4^{0}$ & 2,3 \\
\hline \multicolumn{6}{|l|}{ Здоровье } \\
\hline $\begin{array}{l}\text { Самооценка здо- } \\
\text { ровья (хорошее } \\
\text { и очень хорошее), \% } \\
\end{array}$ & 60 & 48 & 43 & $59^{\circ}$ & 38 \\
\hline $\begin{array}{l}\text { Наличие } \\
\text { хронических } \\
\text { заболеваний, \% } \\
\end{array}$ & 17 & 21 & 23 & 15 & 26 \\
\hline $\begin{array}{l}\text { Постоянная } \\
\text { нехватка времени, } \\
\text { спешка, \% }\end{array}$ & 44 & 32 & 25 & 42 & 32 \\
\hline $\begin{array}{l}\text { Свободное время, } \\
\text { часов в день }\end{array}$ & 3,2 & 3,8 & 4,0 & 3,3 & 3,7 \\
\hline $\begin{array}{l}\text { Количество } \\
\text { наблюдений }\end{array}$ & 3148 & 36630 & 22380 & 12410 & 1840 \\
\hline
\end{tabular}

Примечание. 0 - статистически значимо не отличается от аналогичного показателя для людей, испытывающих "Сэндвич-синдром".

Источник: расчеты автора на данных ВНИСФВ-2019.

\section{3. Методология исследования}

При проведении оценки влияния "сэндвич-синдрома" на показатели здоровья и занятости необходимо учитывать следующие особенности задачи:

- Группа людей, испытывающих "сэндвич-синдром", по наблюдаемым характеристикам существенно отличается от лиц, не испытывающих сэндвич-синдром (см. раздел 2.2).

- Попадание индивидов в группу людей, испытывающих "сэндвич-синдром", скорее всего не является случайным процессом.

В подобных условиях применение простых эконометрических подходов (МНК, моделей бинарного выбора) для определения эффекта “сэндвич-синдрома" может приводить к смещению оценок.

Для определения эффекта "сэндвич-синдрома" на занятость и здоровье индивидов в работе используется метод мэтчинга (matching), который широко применяется для оценки государственных программ и политик [Imbens, 2004; 
Abadie, Imbens, 2006; Abadie, Cattaneo, 2018; Ениколопов 2009]. Базовая идея мэтчинга состоит в подборе контрольной группы: для каждого участника отбираются индивиды с наиболее похожими наблюдаемыми характеристиками из числа неучастников. Оценка эффекта программы производится путем сопоставления исходов/результатов участников программы и неучастников программы, вошедших в контрольную группу. Подобная методика продуктивно борется со смещением оценки эффективности, вызванной различием наблюдаемых характеристик участников и неучастников программы. Метод мэтчинга не решает проблему неслучайности отбора в группу участников (так как факторы отбора могут включать в себя ненаблюдаемые характеристики), но может смягчать проблему (если есть основания предполагать, что ненаблюдаемые характеристики взаимосвязаны с наблюдаемыми).

В настоящее время метод мэтчинга получил распространение в различных исследовательских областях - например, в социологии, экономике, эпидемиологии, в политических исследованиях и т. д. [Stuart, 2010]. Метод мэтчинга также применялся в ряде работ, анализирующих влияние предоставления услуг неформального ухода на социально-экономическое положение и здоровье ухаживающих (например, [Walsh, Murphy, 2018; Di Novi, Jacobs, Migheli, 2015; Bom, Stöckel, 2020; Schmitz, Westphal, 2017]). В работе [Brenna, 2020] метод мэтчинга используется для изучения влияния "сэндвич-синдрома" на вероятность депрессии.

В данной работе в качестве участников программы мы рассматриваем испытывающих "сэндвич-синдром" - соответственно, группу неучастников составляют не испытывающие "сэндвич-синдром" индивиды. Для формирования контрольной группы мы применяем метод ближайшего соседа (nearest neighbor matching). В рамках методики для каждого индивида, испытывающего "сэндвич-синдром" в качестве контрольной группы выбирается $\mathrm{n}$ индивидов, не испытывающих "сэндвич-синдром", с наиболее близкими значениями наблюдаемых характеристик (ковариат) ${ }^{7}$. В качестве ковариат использовались пол индивида, его возраст (непрерывная переменная), образование (4 категории), местность проживания (город или село), федеральный округ проживания (8 категорий). Поскольку гендерная структура лиц испытывающих и не испытывающих "сэндвич-синдром" существенно различается, при формировании контрольной группы мы требовали точное совпадение по полу. В контрольную группу к лицам, испытывающим "сэндвич-синдром", отбирались только индивиды того же пола, не испытывающие "Сэндвич-синдром". Степень близости индивидов на основе остальных ковариат определялась с помощью метрики Махаланобиса:

$$
d\left(x_{s}, x_{n s}\right)=\left(x_{s}-x_{n s}\right) \Sigma^{-1}\left(x_{s}-x_{n s}\right),
$$

где $x_{\mathrm{s}}$ - вектор ковариат индивида, испытывающего "сэндвич-синдром",

$x_{n s}$ - вектор наблюдаемых характеристик индивида, не испытывающего "Сэндвич-синдром",

$\Sigma^{-1}$ - ковариационная матрица ковариат. В работе предполагалось, что человек, не испытывающий “сэндвич-синдром", может войти в контрольную группу

В работе оценка эффекта "сэндвич-синдрома" проводится при различных значениях $n(1,3,5)$. 
индивида, испытывающего “сэндвич-синдром", только в том случае, если мера близости между ними не превышает 1,5.

В работе осуществляется мэтчинг с возвращением - индивид, не испытывающий "сэндвич-синдром" может входить в контрольную группу для разных индивидов, испытывающих "сэндвич-синдром".

Средний эффект “сэндвич-синдрома" на характеристики занятости и здоровья испытывающих "сэндвич-синдром" (ATE) рассчитывался как разность средних величин показателей здоровья/занятости лиц, испытывающих “сэндвич-синдром" и лиц, не испытывающих "сэндвич-синдром", вошедших в контрольную группу:

$$
\operatorname{ATE}=\left(1 / N_{T}\right)\left[\Sigma_{i \in T} Y_{i}^{S}-\Sigma_{i \in C} \omega(i, j) Y_{j}^{C N S}\right] \text {, }
$$

где $Y_{i}^{s}$ - показатель занятости/здоровья $i$-го индивида, испытывающего “сэндвичсиндром",

$Y_{j}^{C N S}$ - показатель занятости/здоровья j-го индивида из контрольной группы,

$N_{T}$ - количество людей, испытывающих "сэндвич-синдром",

$\omega(i, j)$ - веса, которые применяются в том случае, если одному человеку, испытывающему "сэндвич-синдром", соответствуют несколько членов контрольной группы.

Оценивание эффекта “сэндвич-синдрома" проводилось с использованием статистического пакета Stata 14.0 (команда teffect nnmatch).

\section{4. Результаты}

В данном разделе представлены оценки влияния "сэндвич-синдрома" на показатели занятости и здоровья индивидов, полученные с помощью процедуры мэтчинга методом ближайшего соседа для $n=1^{8}$.

\section{1. Влияние "сэндвич-синдрома" на занятость индивидов}

В таблице 3 представлены оценки влияния "сэндвич-синдрома" на показатели занятости (АТT). Среди людей, испытывающих "сэндвич-синдром", уровень занятости на 8.1 п.п ${ }^{9}$. ниже аналогичного показателя в контрольной группе и статистически значимо ниже, чем в любой из рассматриваемых подгрупп людей, не испытывающих “сэндвич-синдром": на 14,4 п. п. ниже, чем для тех, кто ни за кем не ухаживает; на 5,1 п. п. ниже, чем для тех, кто ухаживает только за детьми и на 9,6 п. п. ниже, чем для тех, кто ухаживает только за взрослыми.

Для занятых на рынке труда, "сэндвич-синдром" увеличивает вероятность дистанционной занятости - доля работающих удаленно на 1.1 п. п. выше для тех, кто вовлечен в уход за двумя поколениями, чем среди тех, кто не испытывает "сэндвич-синдром". Полученная оценка практически не варьируется в зависимости от используемой контрольной подгруппы. Необходимо отметить, что речь идет о периоде до пандемии, когда распространенность дистанционной занятости была невелика (см. раздел 3.3).

\footnotetext{
8 При увеличении параметра $\mathrm{n}$ оценки существенно не изменяются. Результаты оценивания при $n=3$ и $n=5$ могут быть высланы по запросу.

9 Для простоты восприятия оценки влияния “сэндвич-синдрома", представленные в таблицах 3 и 4 в долях, обсуждаются в процентных показателях.
} 
"Сэндвич-синдром" также увеличивает вероятность наличия гибкого графика работы у занятых. Однако величина влияния незначительна - 0,4 п. п. При этом эффект достигается за счет различий между теми, кто испытывает "сэндвичсиндром" и теми, кто ухаживает за только за детьми (0,5 п. п.). Сопоставление распространенности гибкой занятости среди лиц, испытывающих "сэндвич-синдром", и среди других рассматриваемых групп не выявило статистически значимых различий.

В работе не было выявлено значимого эффекта “сэндвич-синдрома" на заработную плату индивидов. Заметим, что несмотря на отсутствие текущего эффекта, "сэндвич-синдром" может иметь отсроченный негативный эффект на заработную плату: вынужденные перерывы в работе, накопленные за период двойного ухода проблемы со здоровьем могут негативно сказаться на уровне заработной платы людей, испытывающих "сэндвич-синдром" даже после окончания эпизода ухода [Schmitz, Westphal, 2017]. Для проверки этой гипотезы необходимо наличие соответствующих панельных или ретроспективных микроданных.

Таблица 3. Оценка влияния сэндвич-синдрома на занятость (АTT), $n=1$

\begin{tabular}{|c|c|c|c|c|}
\hline \multirow{3}{*}{ Показатель } & \multicolumn{4}{|c|}{ Контрольная группа } \\
\hline & \multirow[b]{2}{*}{$\begin{array}{c}\text { Не испытывают } \\
\text { "сэндв.-синдром" }\end{array}$} & \multicolumn{3}{|c|}{ Среди них: } \\
\hline & & $\begin{array}{c}\text { Не ухаживают } \\
\text { ни за кем }\end{array}$ & $\begin{array}{c}\text { Ухаживают } \\
\text { только } \\
\text { за детьми }\end{array}$ & $\begin{array}{c}\text { Ухаживают } \\
\text { только } \\
\text { за взрослыми }\end{array}$ \\
\hline $\begin{array}{l}\text { Занятость на рынке } \\
\text { труда, доля }\end{array}$ & $\begin{array}{c}-0,081 * * * \\
{[0,008]}\end{array}$ & $\begin{array}{c}-0,144 * * * \\
{[0,009]}\end{array}$ & $\begin{array}{c}-0,051 * * * \\
{[0,009]}\end{array}$ & $\begin{array}{c}-0,096 * * * \\
{[0,018]}\end{array}$ \\
\hline $\begin{array}{l}\text { Дистанционная } \\
\text { занятость, доля }\end{array}$ & $\begin{array}{c}0,011 * * * \\
{[0,004]}\end{array}$ & $\begin{array}{c}0,010 * * * \\
{[0,004]}\end{array}$ & $\begin{array}{l}0,011 * * * \\
{[0,004]}\end{array}$ & $\begin{array}{c}0,009 \\
{[0,010]}\end{array}$ \\
\hline $\begin{array}{l}\text { Гибкая занятость, } \\
\text { доля }\end{array}$ & $\begin{array}{l}0,004 * \\
{[0,002]}\end{array}$ & $\begin{array}{c}0,002 \\
{[0,003]}\end{array}$ & $\begin{array}{l}0,005^{* *} \\
{[0,003]}\end{array}$ & $\begin{array}{l}-0,000 \\
{[0,007]}\end{array}$ \\
\hline $\begin{array}{l}\text { Заработная плата, } \\
\text { ПМ }\end{array}$ & $\begin{array}{c}0,034 \\
{[0,028]}\end{array}$ & $\begin{array}{l}-0,022 \\
{[0,032]}\end{array}$ & $\begin{array}{l}0,064 * \\
{[, 040]}\end{array}$ & $\begin{array}{c}0,022 \\
{[0,084]}\end{array}$ \\
\hline
\end{tabular}

Примечание. ***, **, *-значимость на 1, 5 и 10\% уровне соответственно. В скобках указаны стандартные ошибки. Источник: расчеты автора на данных ВНИСФВ-2019 г.

\section{2. Влияние "сэндвич-синдрома" на здоровье индивидов}

Результаты оценивания эффекта "сэндвич-синдрома" на показатели здоровья индивидов представлены в таблице 4. Проведенное исследование не выявило статистически значимого влияния "сэндвич-синдрома" на самооценку здоровья индивидов. Тем не менее, как и в случае с заработной платой, нельзя утверждать, что двойной уход не совсем не отражается на самооценке здоровья. В литературе показано, что неформальный уход может оказывать существенный отсроченный эффект на здоровье ухаживающих (например, [Vlachantoni et al., 2016]). 
Индивиды, испытывающие "сэндвич-синдром", имеют повышенный риск хронических заболеваний. Вероятность наличия хотя бы одного хронического заболевания у лиц, осуществляющих двойной уход, на 1,7 п. п. выше, чем у лиц, не испытывающих "сэндвич-синдром". Сопоставление уровня заболеваемости хроническими болезнями лиц, испытывающих "сэндвич-синдром", и различных групп людей, не испытывающих "сэндвич-синдром" показало, что уровень заболеваемости людей, вовлеченных в уход за двумя поколениями статистически значимо выше, чем аналогичный показатель для тех, кто ни за кем не ухаживает (на 1,5 п. п.) и для тех, кто ухаживает только за детьми (на 1,4 п. п.). Распространенность хронических заболеваний среди испытывающих "сэндвич-синдром" и среди лиц, ухаживающих только за взрослыми, не имеет статистически значимых различий.

Ухаживающие одновременно за двумя поколениями значительно чаще испытывают чувство спешки, чем люди, не испытывающие "сэндвич-синдром". Доля тех, кто ощущает постоянную нехватку времени, среди испытывающих “сэндвичсиндром" на 6,1 п. п. выше, чем среди не испытывающих "сэндвич-синдром", на 14,9 п. п. выше, чем среди тех, кто ни за кем не ухаживает и на 8,6 п. п. выше, чем среди тех, кто ухаживает только за взрослыми.

В среднем у людей, испытывающих "сэндвич-синдром" в день на 20 минут меньше свободного времени, чем у остальных. Максимальный негативный эффект "сэндвич-синдрома" на свободное время индивидов наблюдается при сопоставлении группы испытывающих "сэндвич-синдром" и группы тех, кто ни за кем не ухаживает (43 минуты в день). Количество свободного времени в день у испытывающих "сэнвич-синдром" на 35 минут меньше, чем у людей, ухаживающих только за взрослыми, и на 6 минут меньше, чем у людей, ухаживающих только за детьми.

Таблица 4. Оценка влияния сэндвич-синдрома на здоровье (ATT), $\boldsymbol{n}=1$

\begin{tabular}{|c|c|c|c|c|}
\hline \multirow{3}{*}{ Показатель } & \multicolumn{4}{|c|}{ Контрольная группа } \\
\hline & \multirow[b]{2}{*}{$\begin{array}{c}\text { Не испыты- } \\
\text { вают “сэндвич- } \\
\text { синдром" }\end{array}$} & \multicolumn{3}{|c|}{ Среди них: } \\
\hline & & $\begin{array}{c}\text { Не ухаживают } \\
\text { ни за кем }\end{array}$ & $\begin{array}{l}\text { Ухаживают } \\
\text { только } \\
\text { за детьми }\end{array}$ & $\begin{array}{c}\text { Ухаживают } \\
\text { только } \\
\text { за взрослыми }\end{array}$ \\
\hline $\begin{array}{l}\text { Самооценка здоровья } \\
\text { (хорошее и очень } \\
\text { хорошее), доля }\end{array}$ & $\begin{array}{l}-0,003 \\
{[0,009]}\end{array}$ & $\begin{array}{c}0,004 \\
{[0,011]}\end{array}$ & $\begin{array}{l}-0,004 \\
{[0,010]}\end{array}$ & $\begin{array}{c}0,034 \\
{[0,031]}\end{array}$ \\
\hline $\begin{array}{l}\text { Наличие хронических } \\
\text { заболеваний, доля }\end{array}$ & $\begin{array}{l}0,017 * * \\
{[0,007]}\end{array}$ & $\begin{array}{l}0,015 * * \\
{[0,007]}\end{array}$ & $\begin{array}{l}0,014 * * \\
{[0,007]}\end{array}$ & $\begin{array}{l}-0,003 \\
{[0,027]}\end{array}$ \\
\hline $\begin{array}{l}\text { Постоянная нехватка } \\
\text { времени, спешка, } \\
\text { доля }\end{array}$ & $\begin{array}{c}0,061 * * * \\
{[0,010]}\end{array}$ & $\begin{array}{c}0,149 * * * \\
{[0,012]}\end{array}$ & $\begin{array}{c}0,014 \\
{[0,011]}\end{array}$ & $\begin{array}{c}0,086 * * * \\
{[0,032]}\end{array}$ \\
\hline $\begin{array}{l}\text { Свободное время, } \\
\text { часов в день }\end{array}$ & $\begin{array}{c}-0,320 * * * \\
{[0,033]}\end{array}$ & $\begin{array}{c}-0,720 * * * \\
{[0,044]}\end{array}$ & $\begin{array}{c}-0,096 * * * \\
{[0,036]}\end{array}$ & $\begin{array}{c}-0,578 * * * \\
{[0,107]}\end{array}$ \\
\hline
\end{tabular}

Примечание. ***, **, *-значимость на 1, 5 и 10\% уровне соответственно. В скобках указаны стандартные ошибки. Источник: расчеты автора на данных ВНИСФВ-2019 г. 


\section{5. Выводы}

Результаты проведенного исследования показывают, что наличие "сэндвичсиндрома" оказывает статистически значимое негативное влияние на показатели занятости и здоровья индивидов. Уровень занятости на рынке труда среди людей, ухаживающих одновременно за двумя поколениями ниже, чем уровень занятости людей, не испытывающих "сэндвич-синдром". Лица, испытывающие "сэндвичсиндром" чаще работают дистанционно. Они также чаще страдают от хронических заболеваний, чаще испытывают постоянное чувство нехватки времени и имеют меньше свободного времени. Несмотря на то, что в ходе работы не было выявлено значимого эффекта "сэндвич-синдрома" на самооценку здоровья и заработную плату индивидов, к этим результатам нужно относиться в определенной долей осторожности. В зарубежной литературе показано, что эпизоды ухода могут иметь отсроченный негативный эффект на эти показатели [Schmitz, Westphal, 2017; Vlachantoni et al., 2016].

В работе также было проведено сопоставление характеристик занятости и здоровья, людей, испытывающих "сэндвич-синдром", с отдельными группами лиц, не испытывающих "сэндвич-синдром" (ни за кем не ухаживающие, ухаживающие только за детьми, ухаживающие только за взрослыми). Величина и значимость эффектов "сэндвич-синдрома" на характеристики занятости и здоровья индивидов варьируются в зависимости от рассматриваемой контрольной группы. Однако в целом полученные оценки показывают, что люди, ухаживающие одновременно за двумя поколениями, испытывают более высокие риски, как с точки зрения занятости, так и с точки здоровья, по сравнению с любой группой лиц, не испытывающих “сэндвич-синдром". Таким образом, результаты работы подтверждают нашу гипотезу о том, что люди, испытывающие "сэндвич-синдром", являются наиболее уязвимой группой.

Люди, испытывающие "сэндвич-синдром", остро нуждаются в комплексной социальной поддержке. Одним из ключевых направлений такой поддержки является социальная политика, направленная на помощь семьям с детьми, и в частности, на облегчение совмещения родительства и оплачиваемой занятости. В рамках этого направления необходимо расширение форм и увеличение гибкости вариантов предоставления услуг формального ухода за детьми. С другой стороны, люди, испытывающие "сэндвич-синдром", нуждаются в мерах поддержки в связи с осуществлением ухода за взрослыми. В настоящее время в России меры поддержки лиц, ухаживающих за пожилыми и инвалидами, очень ограничены. Необходима разработка и внедрение эффективной системы долговременного ухода, сочетающей в себе различные виды услуг формального ухода, а также специализированные меры поддержки лиц, осуществляющих неформальный уход (меры, направленные на сохранение занятости, обучение навыкам ухода, психологическое сопровождение, консультационная поддержка и др.) [Гришина, Цацура, 2020].

В работе были получены оценки влияния "сэндвич-синдрома" на отдельные характеристики занятости и здоровья людей в РФ. Однако есть основания предполагать, что проблемы людей, ухаживающих одновременно за двумя поколениями, существенно шире. В ходе дальнейших исследований имеет смысл провести ана- 
лиз влияния "сэндвич-синдрома" на расширенный спектр показателей занятости, психического и физического здоровья индивидов, на их самосохранительное поведение, на их участие в социальной жизни и т. д. При этом необходимо изучение как текущих, так и отсроченных эффектов двойного ухода. Особый интерес представляет анализ вариации влияния "сэндвич-синдрома" на различные аспекты жизнедеятельности человека в зависимости от интенсивности ухода. Результаты таких научных работ могут стать базой для формирования эффективной системы поддержки людей, испытывающих “сэндвич-синдром".

\section{Список литературы (References)}

Аникина В., Пшонова К. Взаимосвязь родительских компетенций, эмоционального состояния и уровня родительского стресса матерей детей дошкольного и младшего школьного возраста / Мир науки. Педагогика и психология. 2019. T. 7. № 6. URL: https://mir-nauki.com/PDF/59PSMN619.pdf (дата обращения: 27.10.2021).

Anikina V. O., Psonova K. A. (2019) Correlations between Parental Competencies, Emotional States and Parenting Stress of Mothers of Preschool and Primary School Children. World of Science. Pedagogy and Psychology. Vol. 7. No. 6. URL: https://mirnauki.com/PDF/59PSMN619.pdf (accessed: 27.10.2021). (In Russ.)

Арженовский С., Артамонова Д. Оценка потерь в зарплате женщин с детьми // Прикладная эконометрика. 2007. Т. 7. № 3. С. 66-79.

Arzhenovskiy S., Artamonova D. (2007) Econometric Estimation of the Wage Penalty for the Motherhood. Applied Econometrics. Vol. 7. No. 3. P. 66-79. (In Russ.)

Бирюкова С., Макаренцева А. Оценки “штрафа за материнство" в России// Население и экономика. 2017. Т. 1. № 1. С. 50-70. https://doi.org/10.3897/popecon. 1.e36032.

Biryukova S., Makarentseva A. (2017) Estimates of the Motherhood Penalty in Russia. Population and Economics. 2017. Vol. 1. No. 1. P. 50-70. https://doi.org/10.3897/ popecon.1.e36032 (In Russ.)

Волкова А.С., Кудаева М.М. О поддержке материнства и детства в семейной политике России //Экономика труда. 2019. Vol. 6. № 4. С. 1491-1504. https://doi.org/ 10.18334/et.6.4.41215.

Volkova A.S., Kudaeva M. M. (2019) About Support of Motherhood and Childhood in Family Policy of Russia. Russian Journal of Labor Economics. Vol. 6. No. 4. P. 14911504. https://doi.org/10.18334/et.6.4.41215. (In Russ.)

Гришина Е.Е., Цацура Е.А. Влияние родственного ухода на занятость, здоровье и материальное положение ухаживающих // Демографическое обозрение. 2020. T. 7. № 2. C. 152-171. https://doi.org/10.17323/demreview.v7i2.11142.

Grishina E., Tsatsura E. (2020) The Effect of Caring for Older and Disabled Relatives on the Employment, Health and Economic Status of Caregivers. Demographic Review. Vol. 7. No. 2. P. 152-171 https://doi.org/10.17323/demreview.v7i2.11142. (In Russ.)

Ениколопов Р. Оценивание эффекта воздействия // Квантиль. 2009. № 6. С. 3-14. URL: http:/ /quantile.ru/06/N6.htm (дата обращения: 27.10.2021). 
Enikolopov R. (2009) Estimation of Treatment Effect. Quantile. No. 6. P. 3-14. URL: http://quantile.ru/06/N6.htm (accessed: 27.10.2021). (In Russ.)

Здравомыслова Е., Савченко А. Моральная карьера заботы о пожилых родственниках, страдающих деменцией // Laboratorium: журнал социальных исследований. 2020. T. 12. № 2. C. 90-123. https://doi.org/10.25285/2078-1938-2020-122-90-123.

Zdravomyslova E., Savchenko A. (2020) A Moral Career of Caring for Elderly Relatives Living with Dementia. Laboratorium: Russian Review of Social Research. Vol. 12. No. 2. P. 90-123 https://doi.org/10.25285/2078-1938-2020-12-2-90-123. (In Russ.)

Зимнякова О.С., Глозман Ж.М., Левин О.С. Факторы, влияющие на социальную адаптацию лиц, которые осуществляют уход за больными с развернутой и поздней стадией болезни Паркинсона // Российский медицинский журнал. 2012. № 3. C. $14-17$.

Zimnyakova O.S., Glozman Zh.M., Levin O.S. (2012) Factors Influencing the Social Adaptation of Caregivers of Patients with the Advanced and End Stages of Parkinson's Disease. Russian Medical Journal. No. 3. P. 14-17. (In Russ.)

Казакова Ю.М. Влияние издержек ухода за ребенком дошкольного возраста на предложение труда женщин // Научные труды Лаборатории исследований рынка труда. Препринт WP15/2012/04. М.: ИД ВШЭ, 2012.

Kazakova Yu.M. (2012) Effect of Pre-school Child Care Costs on Women's Labor Supply: Working paper WP15/2012/04. Moscow: Publishing House of the Higher School of Economics. (In Russ.)

Карабчук Т.С., Нагерняк М.А. Детерминанты занятости для матерей в России //Журнал исследований социальной политики. 2013. T. 11. № 1. C. 25-48. URL: https://jsps.hse.ru/article/view/3446 (дата обращения: 29.10.2021).

Karabchuk T.S., Nagernyak M. A. (2013) Employment Determinants for Mothers in Russia. The Journal of Social Policy Studies. Vol. 11. No. 1. P. 25-48. URL: https:// jsps.hse.ru/article/view/3446 (accessed: 27.10.2021). (In Russ.)

Корчагина И.И., Прокофьева Л.М. Население о роли семьи и общества в поддержке детей и престарелых: тенденции последних лет//Народонаселение. 2012. № 3. С. 95-104.

Korchagina I. I., Prokofieva L. M. (2012) Population on the Role of Family and Society in Providing Support to Children and the Elderly: Recent Trends. Population. No. 3. P. 95-104. (In Russ.)

Краснова О. Проблемы семейной помощи и ухода за пожилыми людьми // Психология зрелости и старения. 2001. № 2. С. 5-41.

Krasnova O. (2001) Family Assistance and Care For the Elderly. The Psychology of Maturity and Aging. No. 2. P. 5-41. (In Russ.)

Мальцева М.Н., Шмонин А.А., Мельникова Е.В. Феномен “семейной инвалидности", или Депрессия у родственников, ухаживающих за пациентом с инвалидностью // ученые записки СПбГМУ им. И.П. Павлова. 2016. Т. 23. № . 3. С. 40-43. 
URL: https://www.1spbgmu.ru/images/home/universitet/izdatelstvo/uchenie_ zapiski/0912_макет.pdf (дата обращения: 30.10.2021).

Maltseva M. N., Shmonin A. A., Melnikova E. V. (2016) The Phenomenon of "Family Disability" or Depression in Relatives Caring for Patients with Disabilities. Records of the I. P. Pavlov St. Petersburg State Medical University. Vol. 23. № . 3. P. 40-43. URL: https://www.1spbgmu.ru/images/home/universitet/izdatelstvo/uchenie_ zapiski/0912_макет.pdf (accessed: 30.10.2021). (In Russ.)

Овчарова Л.Н. Новая политика поддержки семей с детьми: кардинальный прорыв или первый шаг?//Мир России. 2008. T. 17. № 2. C. 41-68. URL: https://mirros. hse.ru/article/view/5150 (дата обращения: 30.10.2021).

Ovcharova L. N. New Policy to Support Families with Children: A Fundamental Breakthrough or a First Step? Universe of Russia. 2008. Vol. 17. No. 2. P. 41-68. URL: https://mirros.hse.ru/article/view/5150 (accessed: 30.10.2021). (In Russ.)

Пайе А., Синявская О. Занятость женщин во Франции и России: роль детей и гендерных установок // Эволюция семьи в Европе: Восток-Запад / под ред. Захарова С.В., Прокофьевой Л.М., Синявской О.В. М. : НИСП, 2010. С. 304-352.

Pailhé A., Sinyavskaya O. (2010) Employment of Women in France and in Russia: The Role of Children and Gender Attitudes. In: Zakharov S. V., Prokofieva L. M., Sinyavskaya O.V. (eds.) The Evolution of Family in Europe: East-West. Moscow: IISP. P. 304-352. (In Russ.)

Савенышева С., Заплетина О. Родительский стресс матерей детей раннего и дошкольного возраста: роль социально-демографических факторов // Мир науки. Педагогика и психология. 2019. № 6. URL: https://mir-nauki.com/PDF/65PSMN619. pdf (дата обращения: 30.10.2021).

Savenysheva S., Zapletina O. (2019) Parenting Stress of Mothers of Preschool Children: The Role of Sociodemographic Factors. World of Science. Pedagogy and Psychology. No. 6. URL: https://mir-nauki.com/PDF/65PSMN619.pdf (accessed: 30.10.2021). (In Russ.)

Смирнова Т.В., Смирнов Р.Г. Барьеры принятия институциональных форм заботы о пожилых (на примере частных пансионатов)//Социологические исследования. 2020. № 4. C. 82-89. https://doi.org/10.31857/S013216250009175-5.

Smirnova T. V., Smirnov R. G. (2020) Institutional Elderly Care: Obstacles to Acceptance (the Case of Private Boarding Houses). Sociological Studies. No. 4. P. 82-89. https:// doi.org/10.31857/S013216250009175-5. (In Russ.)

Ткач О. “Заботливый дом": уход за пожилыми родственниками и проблемы совместного проживания//Социологические исследования. 2015. № 10. С. 94-102. URL: https://www.isras.ru/index.php?page_id=2624\&jn=socis\&jn=socis\&jid=5792 (дата обращения: 30.10.2021).

Tkach O. (2015) “Caring Home”: Kin-Related Elderly Care and Issues of Cohabitation. Sociological Studies. No. 10. P. 94-102. URL: https://www.isras.ru/index.php?page_ $i d=2624 \& j n=s o c i s \& j n=s o c i s \& j i d=5792$ (accessed: 30.10 .2021$)$. (In Russ.)

Шерешева М., Калмыкова Н., Колкова К. Старение населения и проблемы поколения "сэндвич»: социально-экономические и психологические аспекты//Вестник 
Балтийского федерального университета им. И. Канта. Серия: Гуманитарные и общественные науки. 2015. № 3. C. 5-14. URL: https://journals.kantiana.ru/ vestnik/3015/8470/ (дата обращения: 30.10.2021).

Sheresheva M., Kalmykova N., Kolkova K. (2015) Population Aging and the Problems of the Sandwich Generation: Socioeconomic and Psychological Aspects. Vestnik Immanuel Kant Baltic Federal University. Humanities and Social Sciences. No. 3. P. 5-14. URL: https://journals.kantiana.ru/vestnik/3015/8470/ (accessed: 30.10.2021). (In Russ.)

Abadie A., Imbens G.W. (2006). Large Sample Properties of Matching Estimators for Average Treatment Effects. Econometrica. Vol. 74. No. 1. P. 235-267. https://doi.org/ 10.1111/j.1468-0262.2006.00655.x.

Abadie A., Cattaneo M.D. (2018) Econometric Methods for Program Evaluation. Annual Review of Economics. Vol. 10. P. 465-503. https://doi.org/10.1146/annureveconomics-080217-053402.

Bardoel E. A., Drago R. (2016) Lifetime Probabilities of Multigenerational Caregiving and Labor Force Attachment in Australia. Demographic Research. Vol. 35. P. 15371548. https://doi.org/10.4054/DemRes.2016.35.52.

Bengtson V. L., Roberts R. E. L. (1991) Intergenerational Solidarity in Aging Families: An Example of Formal Theory Construction. Journal of Marriage and Family. Vol. 53. No. 4. P. 856-870. https://doi.org/10.2307/352993.

Bom J., Stöckel J. (2021) Is the Grass Greener on the Other Side? The Health Impact of Providing Informal Care in the UK and the Netherlands. Social Science \& Medicine. Vol. 269. P. 113562. https://doi.org/10.1016/j.socscimed.2020.113562.

Brandt M., Haberkern K., Szydlik M. (2009) Intergenerational Help and Care in Europe. European Sociological Review. Vol. 25. No. 5. P. 585-601. https://doi.org/10.1093/ esr/jcn076.

Brenna E. (2020) Should I Care for My Mum or for My Kid? Sandwich Generation and Depression Burden in Italy. Health Policy. Vol. 125. No. 3. P. 415-423. https://doi.org/ 10.1016/j.healthpol.2020.11.014.

Chassin, L., Macy, J., Seo, D., Presson, C., Sherman, S. (2010) The Association between Membership in the Sandwich Generation and Health Behaviors: A Longitudinal Study. Journal of Applied Developmental Psychology. Vol. 31. No. 1. P. 38-46. https:// doi.org/10.1016/j.appdev.2009.06.001.

Daatland S., Veenstra M., Lima I. (2010) Norwegian Sandwiches: On the Prevalence and Consequences of Family and Work Role Squeezes Over the Life Course. European Journal of Ageing. Vol. 7. P. 271-281. https://doi.org/10.1007/s10433-010-0163-3.

Do E. K., Cohen S. A., Brown M.J. (2014). Socioeconomic and Demographic Factors Modify the Association between Informal Caregiving and Health in the Sandwich Generation. BMC Public Health. Vol. 14. https://doi.org/10.1186/1471-2458-14-362. 
Di Novi C., Jacobs R., Migheli M. (2015) The Quality of Life of Female Informal Caregivers: From Scandinavia to the Mediterranean Sea. European Journal of Population. Vol. 31. P. 309-333. https://doi.org/10.1007/s10680-014-9336-7.

Fokkema T., Bekke ter S., Dykstra P. (2008) Solidarity between Parents and Their Adult Children in Europe. Amsterdam: Amsterdam University Press. https:// doi.org/10.2307/j.ctt6wp66q.

Gomez-Bernal F., Madva E. N., Puckett J., Amonoo H. L., Millstein R. A., Huffman J. C. (2019) Relationships Between Life Stressors, Health Behaviors, and Chronic Medical Conditions in Mid-Life Adults: A Narrative Review Psychosomatics. Vol. 60. No. 2. P. 153-163. https://doi.org/10.1016/j.psym.2018.12.007.

Häusler N., Hämmig O., Bopp M. (2018) Impact of Parenthood, Informal Caregiving and Its Combination on Self-Rated Health - A Population-Based Study in Switzerland. Journal of Population Ageing. Vol. 11. P. 387-403. https://doi.org/10.1007/ s12062-017-9208-0.

Idler E. L., Benyamini Y. (1997) Self-Rated Health and Mortality: A Review of TwentySeven Community Studies. Journal of Health and Social Behavior. Vol. 38. No. 1. P. 21-37. https://doi.org/10.2307/2955359.

Imbens G. (2004) Nonparametric Estimation of Average Treatment Effects under Exogeneity: A Review. Review of Economics and Statistics. Vol. 86. No. 1. P. 34-29. https://doi.org/10.1162/003465304323023651.

Miilunpalo S., Vuori I., Oja P., Pasanen M., Urponen H. (1997) Self-Rated Health Status as a Health Measure: The Predictive Value of Self-Reported Health Status on the Use of Physician Services and on Mortality in the Working-Age Population. Journal of Clinical Epidemiology. Vol. 50. No. 5. P. 517-528. https://doi.org/10.1016/ S0895-4356(97)00045-0.

Miller D. A. (1981) The "Sandwich" Generation: Adult Children of the Aging. Social Work. Vol. 26. No. 5. P. 419-423. https://doi.org/10.1093/sw/26.5.419.

Pagani L., Marenzi A. (2008) The Labor Market Participation of Sandwich Generation Italian Women. Journal of Family and Economic Issues. Vol. 29(3). P. 427-444. https:// doi.org/10.1007/s10834-008-9112-0.

Pierret C. (2006) The “Sandwich Generation”: Women Caring for Parents and Children. Monthly Labor Review. U. S. Department of Labor, Bureau of Labor Statistics. Vol. 129. No. 9. P. 3-9.

Rubin R., White-Means S. (2009) Informal Caregiving: Dilemmas of Sandwiched Caregivers. Journal of Family Economic Issues. Vol. 30. P. 252-267. https:// doi.org/10.1007/s10834-009-9155-x.

Schmitz H., Westphal M. (2017) Informal Care and Long-Term Labor Market Outcomes. Journal of Health Economics. Vol. 56. P.1-18. https://doi.org/10.1016/j.jhealeco.2017. 09.002. 
Silverstein M., Bengtson V. L. (1997) Intergenerational Solidarity and the Structure of Adult Child-Parent Relationships in American Families. American Journal of Sociology. Vol. 103. No. 2. P. 429-460. https://doi.org/10.1086/231213.

Silverstein M., Gans D., Yang F. M. (2006) Intergenerational Support to Aging Parents: The Role of Norms and Needs. Journal of Family Issues. Vol. 27. No. 8. P. 1068-1084. https://doi.org/10.1177/0192513X06288120.

Stuart E.A. (2010) Matching Methods for Causal Inference: A Review and a Look Forward. Statistical Science. Vol. 25. No. 1. P. 1-21. https://doi.org/10.1214/ 09-STS313.

Vlachantoni A., Robards J., Falkingham J., Evandrou M. (2016) Trajectories of Informal Care and Health. SSM-Population Health. Vol. 2. P. 495-501. https:// doi.org/10.1016/j.ssmph.2016.05.009.

Voydanoff P., Donnelly B. (1999) Multiple Roles and Psychological Distress: The Intersection of the Paid Worker, Spouse, and Parent Roles with the Role of the Adult Child. Journal of Marriage and the Family. Vol. 61. No. 3. P. 725-738. https:// doi.org/10.2307/353573.

Walsh E., Murphy A. (2018) Investigating the Causal Relationship between Employment and Informal Caregiving of the Elderly. BMC Res Notes. Vol. 11. https://doi.org/ 10.1186/s13104-018-3684-z.

Wu S., Wang R., Zhao Y., Ma X., Wu M., Yan X., He J. (2013) The Relationship between Self-Rated Health and Objective Health Status: A Population-Based Study. BMC Public Health. Vol. 13. https://doi.org/10.1186/1471-2458-13-320. 